\title{
Study on Government Functions in Privatization of Public Stadiums- Based on Effective Supply of Double-level System
}

\author{
FenghuaYang ${ }^{1, *}$ \\ ${ }^{1}$ Jianghan University of Physical Education ,Wuhan, China
}

\begin{abstract}
In the two-level system of effective supply of public stadiums, institutional supply is the constraint of product supply, and product supply feeds back to the formation of institutional supply. The establishment and change of the government function supply system is the key to the efficiency of privatized product supply. Therefore, the government in the process of privatization of public stadiums and gymnasiums in our country will realize the corresponding and complete regulatory functions before entering, during access, during implementation and after exit.
\end{abstract}

\section{Introduction}

In 2019 , the total output of the national sports industry was 2948.34 billion yuan, of which the total output of sports venues and facility management and the construction of sports facilities was 368.87 billion yuan, accounting for $12.5 \%$. The number of sports venues in 2019 was 3.544 million, and public sports venues such as institutions and agencies accounted for 79.9\%[1].The privatization supply mode of public sports venues is one of the important representative forms of diversified supply. How to realize the effective supply of government functions in the privatization process of the effective supply of public sports venues and effectively improve the supply efficiency of public sports venues, these problems Research is of great significance for promoting the privatization reform of public stadiums in China.

\section{Understanding of the effective supply of public stadiums}

Effective supply refers to the supply that can create effective demand, and the products pushed to the market can be absorbed by market demand [2]. Domestic sports scholars [3] discuss the characteristics and trends of the demand and supply of competitive sports, community sports, and farmer sports on the concept of effective supply mainly through the relationship between supply and demand [4]. "Supply-side reform" is the first time that the Chinese government has clearly proposed macroeconomic reforms from the "supply" side. Its reform practice and the formation of China's new supplyside economics believe that all social entities should perform their duties and cooperate in optimizing the allocation. Analyze the new characteristics and new trends of diversified subject relationships in economic development. The effective supply of public stadiums is to pay more attention to the positive effect of the supply side on the benefits of stadiums, and to realize the effective supply of public stadiums under China's more complicated national conditions [5]. The "supply-side structural reform" emphasizes starting from the supply side and promoting structural reforms at the three levels of system, mechanism, and technology to liberate productivity, enhance competitiveness and promote economic development. The supply-side reform proposal promoted by the new supply economics provides the foundation for the deepening of the effective supply of public sports venues, and strengthens the development direction of promoting the reform of public sports venues from the supply side; focusing on demand-oriented supply management, through "double reduction" and the "dual supporting" policy creates an optimized environment for policy supply for public sports venues, and realizes the role positioning from the benign interaction between the government and the market and the complementary "double in place" prompts the formation of a good social synergy, from the state-owned and non-state-owned economy. "Double-entry" realizes the coordinated development of diversified participants in sports venues, and realizes the transformation and upgrading of supply from the "double innovation" of public sports venues' own innovation and entrepreneurship.

The study believes that the effective supply of public sports venues refers to the formation of government functional supply through the construction of a four-inone diversified cooperative supply system of government, market, enterprise, and society. The selection and supply of the supply mechanism under market competition and the supply of service products by enterprises and social organizations The multi-dimensional and integrated sustainable supply can achieve the supply of the effective demand of the public sports stadium industry, so that the service products of the public sports stadium can be

*FenghuaYang :yangfenghua@jhun.edu.cn 
absorbed by the market, and the public demand can be appropriately met [6].

\section{Two-level theoretical system for effective supply of public stadiums}

The two-tier theoretical construction of the effective supply of public stadiums emphasizes the measurement of the effectiveness of supply from two levels (Figure 1).

The first level is institutional supply. It is to provide an institutional platform for the effective supply of products, and is the foundation and key to the ultimate effective supply of products. As far as institutional supply is concerned, it is considered from the macro level and the meso level. The meso level refers to the arrangement of the provision mechanism, which includes the definition of the "power" of the public stadium resources under the leadership of the government, and the question of whether it is reasonable to construct a diversified market participant. The arrangement of the supply mechanism mainly involves the construction of a diversified supply body pattern and the public choice of supply methods. The research is on the issue of the supply body and the supply method. Government function is not only the main content of system supply, but also the main way to form mechanism supply. Therefore, the supply of government functions is more critical to the privatization of public sports stadiums in China.Data from my country's sixth census of sports venues shows that there are 1,694,600 sports venues. From the perspective of investment entities, my country's sports venues are mainly governmentinvested and constructed, and government functions are dominant. Among them, the state-owned economy accounted for $30.6 \%$, the collective economy accounted for $25.5 \%$, the enterprise (private) accounted for $23.0 \%$, the private accounted for $12.8 \%$, and the remaining $8.1 \%$ was foreign investment. In terms of the business model of large stadiums, independent operations accounted for $90.1 \%$; cooperative operations accounted for $3.8 \%$; and commissioned operations accounted for only $6.1 \%[7]$.

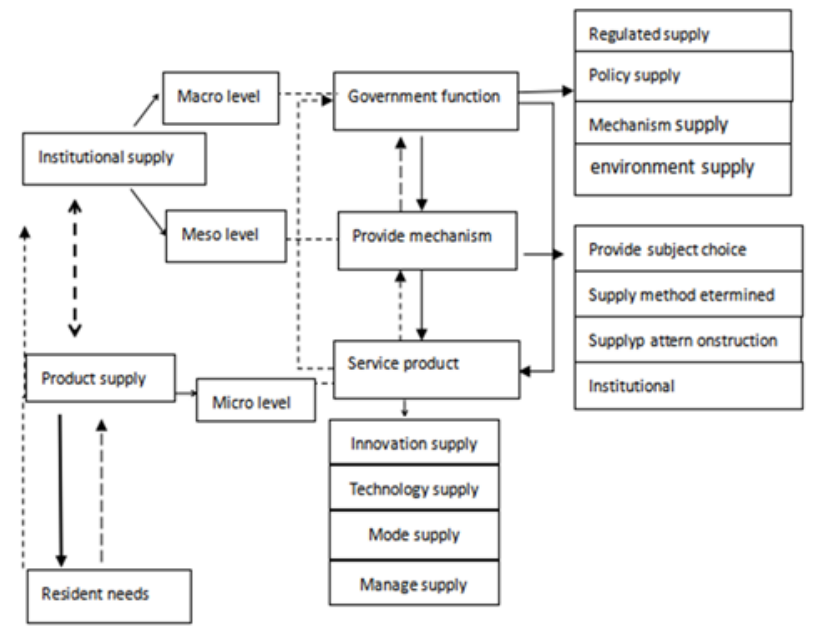

Figure 1. Two-level system of effective supply of public stadiums.

The second level is product supply. From the level and structure of effective supply, as far as product supply is concerned, it is considered from the micro level, which in fact refers to the embodiment of product supply efficiency. The content is based on the resources of public sports venues, and embodies the overall supply scale, specific supply mode, operation and management level, technological transformation and renewal degree, service quality level, and service product innovation. There is no doubt that the purpose of product supply is to meet the effective realization of public demand. System supply, product service supply and social residents' demand constitute the supply and demand system of public sports venues. Due to the ownership of sports venues in my country, the efficiency of product supply is low, which is reflected in the poor operating level and serious losses. In 2013 , the revenue of my country's sports venues was 64.61 billion yuan, the expenditure was 66.26 billion yuan, and the profit rate was $-2.6 \%$. The relationship between the three is not a simple one-way relationship, but a multidirectional relationship.

\section{Analysis under the two-tier system of effective supply of public stadiums}

The two levels of public stadium service supply influence each other. The first-level institutional supply becomes the constraint of the second-level public venue product supply. The establishment and changes of institutional supply will change the supply performance and supply constraints of the actual supply entities in the public venue services. The second-level feedback on the supply of public venues is based on the formation of institutional supply. The marketization of the supply of public venues can provide real feedback on the contradiction between supply and demand and the efficiency of venue public services, and provide goals or needs for institutional changes. The contradiction between the supply and demand of public sports services and the improvement of efficiency cannot be solved only in the unified level of product supply or system supply. The two-tier supply system for the effective supply of public sports venues requires the cooperation of public and private sectors, that is, through multi-level delegation and information feedback among sports consumers, sports venues suppliers, and government agencies.

The relationship between the service providers of public sports venues is further explained below:

First, residents based on their personal sports consumption preferences and interest collections, based on the efficiency mechanism with dynamic compensation, launch the game selection of public stadium services, and determine the system supply of public stadiums, including: public-private cooperation model, cost sharing or compensation mechanism, various The total scale and structure of the supply of various venue services. In the process of continuous evolution and selection, the supply of venue systems will be implemented and embodied in the form of national or government organizations, and in the form of government legislation or regulations, it will become a system for companies or organizations to provide fair competition for venue services and franchise rights. The restriction conditions of regulations, so as to achieve the efficiency of the public venue system. That is 
to form the first level of supply: institutional service supply.

Second, under the constraints of the products of the system of public stadiums, enterprises or social organizations participate in competition for the supply of public stadiums and stadiums according to their own strength and interest goals to achieve the efficiency of the supply of stadiums and stadiums. The government entrusts the franchise of the supply of sports venues to enterprises or social organizations, which implement the supply of venue products, that is, the second level of supply: the micro service supply of public sports venues [6].

Third, the information exchange and feedback of the public sports stadium service supply are constantly playing games among the government, enterprises, and residents. On the one hand, consumers comprehensively evaluate consumer expenditures and the utility of the overall public stadium services based on the current situation of the micro-service supply of the venues to determine whether the game strategy in the selection of public stadium services will change or not, which can directly affect the supply status of venue policies and regulations. On the other hand, the government, based on the results of multiple games of public choice, determines the rules for companies to participate in supply competition and other institutional products, and implements supervision of the supply of corporate venue services. Finally, under the constraints of rules and regulations and government supervision, enterprises participate in the franchise competition for micro-services of public stadiums and provide stadium services according to residents' preferences. This kind of game process between the three is the key to ensure the effectiveness of the double-tier supply of the stadium service system.

Fourth, affected by the bounded rationality of consumers, the level of economic consumption and the differences in individual demand for venue services, the venue service supply process presents a dynamic development process: institutional product supply is constantly changing, public-private cooperation models are constantly changing, venue services Direct supply is in a complex and changeable form in the form of constant competition. This process reflects people's rational choices and the evolution of human economy and society. Therefore, the benign operation of the two-tier supply mechanism of public stadiums is an effective mechanism to improve the supply efficiency of public stadiums and solve the contradiction between the supply and demand of stadiums.

\section{Effective supply of government functions in a two-tier system}

The effective supply of public stadiums and stadiums focuses on two aspects: system supply and service product supply. From the perspective of the construction of the supply mechanism, the privatization of public sports stadiums, as a new force in the diversified supply mechanism, although in the initial stage of development, has gradually become an effective measure and an important representative form for realizing the diversified supply mechanism. It is also a public sports One of the inevitable choices for the market-oriented reform of venues.

According to the two-level theory of effective supply of public sports venues, government function supervision (supply) is the key in the process of privatization of public sports venues. Its meaning includes: First, to realize the effectiveness of the supply mode arrangement that the effective supply of public sports venues depends on. This mainly revolves around the selection of the supply mode of public stadiums and the construction of a diversified supply pattern. It solves the problems of how to supply and by whom, and ultimately realizes the effectiveness of the operation and management of public stadiums, which inevitably involves the arrangement of government functions. Second, realizing the effective supply of public sports venues also depends on the effectiveness of the government's supply of functions under the diversified supply of public sports venues. This refers to the means and supporting methods used by the government and its institutions to provide public goods effectively and efficiently in the implementation of the policy of further supply mode. That is to say, the government correctly positions according to the functional needs in the formation of a diversified supply pattern., To establish a reasonable supervision system to ensure the realization of privatization. It should be clear that the government is in an extremely important position in the selection of the supply mode of public goods and the promotion of changes in the supply mode. Therefore, at this level, the demand generated by the government based on the impact and requirements of privatization on government functions is the basis for defining government roles or transforming government functions, and implementing government management through regulations and other means is its implementation process [7].

\section{Links to the advancement of government functions}

Based on the theoretical framework of a two-tier system of effective supply, in the process of privatization of public sports venues, the establishment and change of government supervision function supply is a key link in achieving privatization supply efficiency. It can be understood from five aspects: First, how the government Carry out regulation and guidance of diversified supply system arrangements to promote the privatization process; second, how the government can effectively select private representatives who can complete public performance to enter the public sports stadium service; third, how the government is in the process of privatization of stadiums Effectively implement supervision responsibilities to ensure that private clients complete the services of public sports venues. Fourth, how the government assumes the corresponding functions or responsibilities when private sponsors of public sports venues withdraw abnormally. The fifth is how the government strengthens its own 
management and fulfills its responsibilities in the process of privatization.

\section{Implementation of government functions}

Considering the government's exercise of power from the different stages of the privatization process of public venues to ensure the realization of functions or responsibilities, it is directional and operational, and it is also more systematic and complete. First, before the privatization of public stadiums and gymnasiums, the government's functions were mainly: guiding functions and institutional arrangements. From the current empirical research before privatization, the government's guiding function is being strengthened, and the functional boundaries of institutional arrangements are still unclear. According to the previous practice of the specific arrangements of the privatization system, it is recommended that the government take further steps before privatization. Good policy guidance. Second, the government's functions in the privatization of public stadiums are mainly: the function of disclosing access information, the function of selecting quasi-providers, and the function of ensuring public participation. In the process of access, the government began to pay attention to fairness, actively promoted the privatization of venues and public access information, and took the initiative to select the most suitable quasi-providers. However, it is still more in terms of arranging the hearing system of various stakeholders and guiding the public to participate in decision-making Lack of strength. Third, the government functions in the implementation of privatization of public sports stadiums are mainly: the function of price regulation, the function of service quality regulation, and the supervision function of preventing monopoly. In the implementation, the government's price regulation and quality regulation functions are deepening, but the supervision function of preventing monopoly is still weaker. Fourth, the government's functions after the withdrawal of privatization of public sports venues are mainly: exercise of escrow functions, compensation responsibilities, compensation responsibilities, and risk sharing responsibilities. After the withdrawal, the government has specific performances in exercising its escrow function, but there are deficiencies in compensation responsibilities, compensation responsibilities and risk sharing responsibilities; the government's self-regulation function is not paid enough attention. Fifth, the government, as the arranger, decision maker, and regulator of the privatization of public sports venues, needs to selfmanage government agencies while performing various responsibilities to achieve the performance of government public services. In the case of privatization, the lack of government responsibilities and inactions, the misplacement of management and the exercise of powers, abuse of power, and other behaviors must be held accountable to improve administrative efficiency and safeguard public interests and the rights of operators.

\section{Conclusion}

The two-tier structure of the effective supply of public stadiums and gymnasiums emphasizes the key to the supply of government functions as a system. Therefore, the government must assume its major responsibility for guarantee and supervision in the process of privatization, and need to specifically reflect its various regulatory responsibilities in each stage of privatization, so as to realize the effectiveness of privatization supply.

\section{References}

1. Announcement on the total scale and value-added data of the national sports industry in 2019 [EB/OL].http://sports.xinhuanet.com/c/202011/03/c 1126691918.htm

2. Hu Peizhao. Theory of Effective Supply[M]. Beijing: Economic Science Press. 2004,415

3. Zhang Yongjun.Study on the Demand and Supply Characteristics of Sports Products in a Consumptionled Economy[J].Journal of Guangzhou Sport University,2005,25(1):10-15

4. Lu Wenyun.Study on the Effective Supply of my country's Olympic Games Honor-winning Competitive Sports Service Products[J].Sports Science,2006,26(12):77-84

5. Ying Jianhua,Lu Hengbo,Liu Zunjia.Research on the Construction of Supervision System for Entrusted Operational Public Stadiums-Taking Zhejiang Province as an Example.[J].Journal of Chengdu Sport University,2012,38(5):26-30

6. Yang Fenghua.Research on the Evolution of Policies and Regulations for Public Stadiums in my country[J].Journal of Chengdu Sport University,2014,40(2):37-42

7. Data compilation of the sixth national census of sports venues [EB/OL].http://www.sport.gov.cn/pucha/index.html

8. Zheng Meiyan.Construction of a comprehensive quality evaluation system for service outsourcing of public stadiums and gymnasiums[J].Journal of Physical Education,2016,23(1):72-75 